\title{
Estudio Comparativo de Dos Técnicas de Plastinación
}

\author{
Two Different Plastination Techniques Comparative Study
}

Fabio Valdés; Eduardo Vega \& Marcos Valenzuela

\begin{abstract}
VALDÉS, F.; VEGA, E. \& VALENZUELA, M. Estudio comparativo de dos técnicas de plastinación. Int. J. Morphol., 28(3):783$786,2010$.

RESUMEN: La técnica de plastinación es utilizada ampliamente para la mejor preservación de las piezas cadavéricas utilizadas en docencia. Nuestra unidad la está utilizando desde el año 2002, pero hemos notado que la calidad de las muestras no es la óptima, produciéndose gran retracción de éstas. Por tal motivo, se diseñó una trabajo que compara la técnica de plastinación de nuestra unidad, con otro proceso, el cual se basa en el protocolo utilizado por la Universidad de Murcia. Utilizamos 24 muestras frescas de riñones y hemiencéfalos de vacuno, riñones y corazones de cerdo y miembro inferior humano, las cuales fueron fijadas con alcohol etílico, formalina y solución fijadora Universidad de los Andes. Fueron aplicadas dos diferentes técnicas de plastinación: una basada en el protocolo utilizado hasta ese momento en nuestro laboratorio de plastinación (técnica A) y otro proceso similar al publicado por la Universidad de Murcia (técnica B). Se evaluaron los porcentajes de variación de peso, ancho, largo, espesor y perímetro de las diferentes piezas plastinadas. También se procedió a fijar las muestras en diferentes soluciones (alcohol, formalina 10\% y solucion fijadora Universidad de los Andes), pesar y medir sus dimensiones. El porcentaje de pérdida de peso promedio fue $63,1 \%$ para la técnica A y 37,9\% para la técnica B $(\mathrm{p}<0,01)$; las mediciones de las disminuciones en el largo, ancho y grosor de las muestras también fueron mayores en las piezas sometidas a la técnica A, siendo todos los porcentajes de pérdidas estadísticamente significativos. Al comparar las muestras según los diferentes métodos de fijación con la técnica B no hubo diferencias estadísticamente significativas. La plastinación de muestras basadas en la técnica de Murcia obtiene muestras de mejor calidad y menos retracción. No influiría en el proceso de plastinación el método de fijación.
\end{abstract}

PALABRAS CLAVE: Preservación de tejidos; Silicona; Acetona; Vacío.

\section{INTRODUCCIÓN}

La técnica de plastinación de piezas cadavéricas, creada en Alemania en la década de los setenta por Günter von Hagens, ha facilitado notablemente la preservación del material anatómico para el estudio y la docencia (von Hagens et al., 1987; Latorre et al., 2007). La difícil obtención de cadáveres en Chile ha impulsado el desarrollo de diferentes laboratorios de plastinación en nuestro país. La Unidad de Anatomía Normal de la Universidad de los Andes, comenzó a desarrollar la técnica el año 2002 y con el tiempo nos hemos encontrado con diferentes problemas en la técnica para obtener muestras adecuadas para la docencia. Una de nuestras principales dificultades consistía en que las piezas quedaban muy retraídas al final del proceso, por lo que perdían su forma original y no eran adecuadas para ser utilizadas.

La literatura señala diferentes procesamientos de las muestras para plastinación en silicona, tanto a temperatura ambiente como en frío (Bravo, 2006; de Jong \& Henry, 2007; Henry, 2007a, 2007b), dependiendo del tipo de siliconas utilizadas. Clásicamente se recomienda que las etapas iniciales de deshidratación con acetona sean en frío (entre $5^{\circ} \mathrm{C}$ a $-20^{\circ} \mathrm{C}$ ) para evitar el problema de la retracción.

El objetivo de este estudio fue comparar la retracción de los tejidos con la técnica de plastinación, con siliconas utilizada por nuestra unidad de anatomía con una técnica similar a la ocupada en la Universidad de Murcia (de Jong \& Henry), institución pionera y respetada internacionalmente en el campo de la plastinación. Secundariamente, se observaron las diferencias de tamaño y peso en las muestras plastinadas con la técnica de mejor rendimiento, y se evaluó si influye en el proceso de fijación el tipo de agente químico utilizado (alcohol, formalina o solución fijadora de la Universidad de los Andes). 


\section{MATERIAL Y MÉTODO}

Se utilizaron muestras anatómicas de cadáveres humanos y animales. Éstas correspondían a cortes transversales de miembro inferior humanas (tipo medallón) y muestras de órganos de porcino y vacuno. Se categorizaron las muestras y se separaron en diferentes grupos según técnica de plastinación y luego, subgrupos, según técnica de fijación. Previo al proceso de fijación las muestras fueron fotografiadas, medidas y pesadas. Las mediciones de ancho, largo y espesor se realizaron en todas las piezas (a excepción del espesor en las muestras de corazón) con el pie de metro marca Mitutoyo ${ }^{\circ}$ (precisión de $0,05 \mathrm{~mm}$ ). Para la variable peso, previo a lavados repetidos y extracción de los restos de sangre y coágulos de su interior, se utilizó en cada oportunidad de medición una balanza electrónica marca Radwag ${ }^{\circledR}$ (precisión de $0,01 \mathrm{mg}$ ). Por último, para la variable diámetro (utilizada sólo en las 3 muestras de corazón) se utilizó el diámetro obtenido en el surco atrio ventricular con una huincha de medir 1,50 (costura). Todos los puntos de mediciones en las muestras fueron marcados con hilo de sutura para su posterior reconocimiento y aplicación de nuevas mediciones en la etapa final del proceso. Se separaron las muestras en 2 grupos: técnica A (Universidad de los Andes) y técnica B (basada en Universidad de Murcia) y en subgrupos con diferentes métodos de fijación (formalina al 10\%, alcohol etílico al 96\% y solución fijadora Universidad de los Andes) con la técnica que produjese la menor retracción. Las piezas fueron fijadas por inmersión en las diferentes soluciones por 7 días para luego comenzar el proceso de plastinación. Tecnica A: deshidrataciones de las muestras con acetona en concentraciones crecientes desde $65 \%$ hasta $100 \%$ a $4^{\circ} \mathrm{C}$ en un tiempo de 35 días; luego impregnación forzada con silicona (Silicones, Inc. ${ }^{\circledR}$ XT-295) en cámara de vacío a $-20^{\circ} \mathrm{C}$; posteriormente colocación de la piezas en bolsas por $18 \mathrm{hrs} \mathrm{a} \mathrm{-}$ $20^{\circ} \mathrm{C}$ para luego polimerizar con gas BIODUR S 6® en cámara de vidrio por 10 días. Técnica B: Deshidratación rápida de las muestras en acetona (baños de $97 \%$ y $100 \%$ ) a $-20^{\circ} \mathrm{C}$; impregnación forzada con silicona (Silicones, Inc. ® XT-295) en cámara de vacío a $-20^{\circ} \mathrm{C}$; retiro de exceso de silicona en periodo de 1 semana; polimerización con gas BIODUR S 6® por $72 \mathrm{hrs}$. Finalmente las muestras fueron medidas y pesadas durante el proceso en las etapas de postfijación, postdeshidratación y postplastinación, de la misma manera que se hizo en un comienzo.

\section{RESULTADOS}

De un total de 24 muestras, 6 de ellas fueron medallones de miembro inferior humano; 6 de muestras porcinas de las cuales 3 eran de corazón y 3 de riñón; y finalmente, 12 muestras de vacuno de las cuales 6 eran de encéfalo y 6 de riñones. Del total de muestras $(n=24), 15$ de ellas se plastinaron usando la técnica $\mathrm{A}$ y 9 con la técnica $\mathrm{B}$. $\mathrm{Al}$ comparar ambas técnicas (A y B) en sus etapas de prefijacion (muestras frescas) versus postplastinación (resultado final) se encontró que todos los deltas, es decir, las diferencias de las variables analizadas de medición y peso, eran estadísticamente significativas (Tabla I), siendo la técnica de B la que demostró menores cambios en las variables analizadas. Cuando se analizaron las principales variables (peso, longitud y ancho) de las diferentes etapas (prefijación, postfijación, posdeshidratación y postplastinación) y se com-
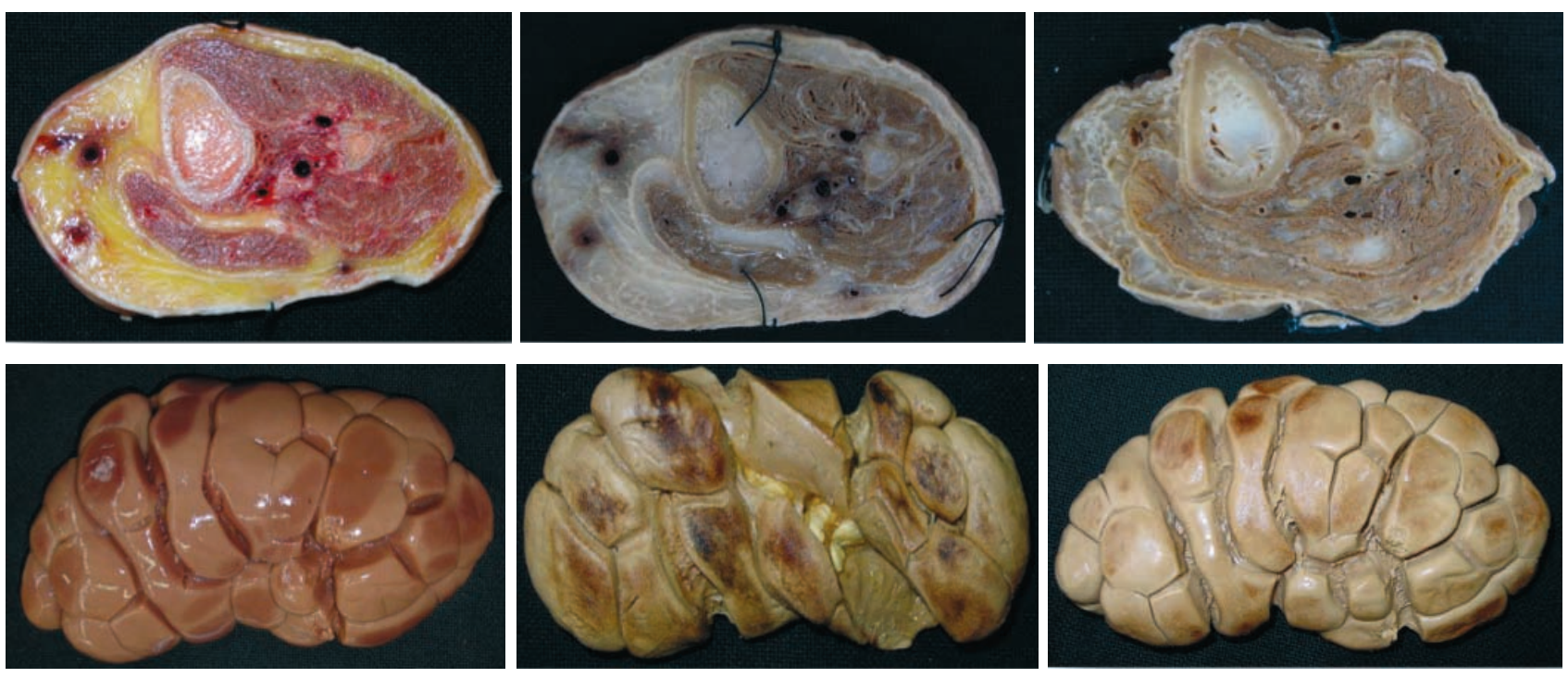

Fig. 1. Muestras de medallones de miembros inferiores humanos y riñones de vacuno: pieza fresca, pieza plastinada con la técnica A, y pieza plastinada con la técnica $\mathrm{B}$. 
Tabla I. Diferencia de las mediciones (en porcentaje) de las muestras al inicio y final del proceso de plastinación.

\begin{tabular}{lccl}
\hline & Técnica A $\%$ & Tecnica B \% & \multicolumn{1}{c}{$\mathrm{p}$} \\
\hline dpeso & 63,1 & 37,9 & 0,001 \\
dlargo & 28,6 & 13,8 & 0,0001 \\
dancho & 29,1 & 16,8 & 0,0072 \\
dgrosor & 31,1 & 17,1 & 0,015 \\
\hline
\end{tabular}

Tabla II. Diferencias de las mediciones (en porcentaje) de las muestras al inicio y al final del proceso de plastinación con la técnica B sometidas a diferentes métodos de fijación

\begin{tabular}{lcccc}
\hline & Alcohol \% & Formalina $\%$ & Sol. Cons. \% & $\mathrm{p}$ \\
\hline dpeso & 39,5 & 44,3 & 55,4 & $>0.05$ \\
dlargo & 14,1 & 18,5 & 23,6 & $>0.05$ \\
dancho & 17,6 & 21,3 & 27,3 & $>0.05$ \\
dgrosor & 24,6 & 15,8 & 27,6 & $>0.05$ \\
\hline
\end{tabular}

pararon entre las diferentes técnicas de plastinación, se encontró una pérdida estadísticamente significativa $(\mathrm{p}<0,05)$, luego de la etapa de deshidratación de las piezas.

Analizando los diferentes métodos de fijación aplicados en la técnica B, se demostró que no existe diferencia estadísticamente significativa para ninguna de las técnicas de fijación utilizadas (Tabla II).

\section{DISCUSIÓN}

Hoy en día la técnica de plastinación se ha convertido en un gran apoyo en la enseñanza de morfología, especialmente en nuestro medio, como consecuencia de la dificultad de obtención de muestras frescas cadavéricas para el estudio y la docencia. La literatura reconoce ampliamente la utilidad de esta técnica (Bravo; Latorre et al.) por lo que hemos concentrado nuestros esfuerzos en ir perfeccionándola a lo largo de los años. Uno de nuestros principales problemas en la plastinación era la importante retracción de las muestras, lo que las dejaba deformadas y en ocasiones poco útiles para la docencia. Nuestro análisis previo nos hacia creer que en la etapa de deshidratación con acetona estaba el problema. Comparamos nuestros procesos con los de la Universidad de Murcia, entidad reconocida internacional-mente en el campo de la plastinación. La gran diferencia en estos procesos está en la etapa de deshidratación con acetona: en Murcia es a $-25^{\circ} \mathrm{C}$ y nuestra unidad la realizaba a $4^{\circ} \mathrm{C}$. Si bien en las diferentes publicaciones recomendaban ejecutar esta etapa a temperaturas bajas, no creíamos en un comienzo que este punto era crucial (Rivera et al., 2009).
La acetona es un potente agente deshidratante de muestras, y a temperaturas ambiente tiende a evaporarse con facilidad (su punto de ebullición es de $56,3^{\circ} \mathrm{C}$ ). Las muestras deshidratadas a $4^{\circ} \mathrm{C}$ (técnica A) demuestran una gran retracción de tejidos, en comparación con las piezas deshidratadas a temperaturas bajo cero con la técnica B (Figura 1). Esto se debe probablemente a que no es suficiente mantener las muestras a temperaturas cercanas a cero, ya que igual hay evaporación de acetona, perdiéndose este líquido de los tejidos (que reemplaza el agua), con la consecuente pérdida de peso y tamaño de las piezas. Por otro lado, la temperatura también influye en la etapa de impregnación forzada, ya que las siliconas utilizadas presentan diferentes viscosidades según la temperatura en que se trabaje, por lo que su ingreso a los tejidos podrá verse afectado al cambiar las temperaturas (de Jong \& Henry, 2007; Henry, 2007a, 2007b). Finalmente, quisimos evaluar si el método de fijación influía en el resultado final de las muestras utilizando la misma técnica de plastinación. No hubo diferencias significativas estadísticamente en cuanto a cambios de peso y dimensiones, aunque visualmente las muestras fijadas en alcohol tenían una mejor apariencia.

\section{AGRADECIMIENTOS.}

Agradecemos la ayuda brindada por el Dr. Rafael Latorre L. quien nos recibió en las dependencias de su Laboratorio de Plastinación en la Universidad de Murcia y nos acompañó en Chile asesorándonos en las modificaciones en nuestro laboratorio de la Universidad de Los Andes. 
VALDÉS, F.; VEGA, E. \& VALENZUELA, M. Two different plastination techniques comparative study. Int. J. Morphol., 28(3):783$786,2010$.

SUMMARY: The plastination technique is used extensively for the improved preservation of cadavers used for teaching. Our unit has been using this technique since 2002, but we have noticed that sample quality is not optimal, given the large retraction of samples. Therefore, a project was designed that compares our department's plastination technique, with another process, based on the protocol used by Murcia University. We used 24 fresh bovine kidneys and brain samples, pigs' kidneys and hearts and human lower limbs; all of which were fixed with ethyl alcohol, formalin and De los Andes University's fixation solution. Two different plastination techniques were applied: one based on the protocol used in our laboratory (technique A) and another one similar to that published by Murcia University (technique B). We evaluated the body weight percentage, width, length, thickness and perimeter of the different plastinated pieces, as well as measuring the same variables in each fixation solution (alcohol, formalin fixative solution 10\% and Universidad de los Andes). The average weight loss percentage was $63.1 \%$ for technique $A$ and $37.9 \%$ for technique $B(p<0.01)$. The decrease measurements in length, width and thickness were also higher under technique A, all percentages being statistically significant. When comparing the samples according to different fixation methods, there were no significant differences. Plastination based on Murcia University's technique obtained better quality samples with less shrinkage. The plastination process was not influenced by the fixation method.

KEY WORDS: Tissue Preservation; Silicone; Acetone; Vaccum.

\section{REFERENCIAS BIBLIOGRÁFICAS}

Bravo, H. Plastinación, una Herramienta Adicional para la Enseñanza de la Anatomía. Int. J. Morphol., 24(3):475$80,2006$.

de Jong, K. \& Henry, R. W. Silicone plastination of Biological tissue: cold-temperature technique Biodur S10/S15 technique and products. J. Int. Soc. Plastination, 22:2-14, 2007.

Henry, R. W. Silicone plastination of biological tissue: coldtemperature technique North Carolina technique and products. J. Int. Soc. Plastination, 22:15-9, 2007 a.

Henry, R. W. Silicone plastination of biological tissue: roomtemperature technique North Carolina technique and products. J. Int. Soc. Plastination, 22:26-30, 2007 b.

Latorre, R. M.; García-Sanz, M. P.; Moreno, M.; Hernández, F.; Gil, F.; López, O.; Ayala, M. D.; Ramírez, G.; Vázquez, J. M.; Arencibia, A. \& Henry, R. W. How useful is plastination in learning anatomy?. J. Vet. Med. Educ., 34(2):172-6, 2007.

Rivera, M. C.; Bonino, F.; Fioretti, C.; Galán, M.; Gigena, S.; Moine, R.; Mouguelar, H.; Natali, J. \& Quinteros, R. Análisis Multivariado Aplicado a la Etapa de Deshidratación en la Técnica de Plastinación del Riñón de Caballo. Int. J. Morphol., 27(3):855-9, 2009.

von Hagens, G.; Tiedemann, K. \& Kriz W. The current potencial of plastination. Anat. Embryol., 175:411-21, 1987.
Dirección para correspondencia:

Dr. Fabio Valdés G.

Avda. San Carlos de Apoquindo 2200

Santiago

CHILE

Fono: $56-2-4129307$

Email: fvaldes@miuandes.cl

Recibido : 11-06-2010

Aceptado: 12-07-2010 